\title{
Hilar control during laparoscopic donor nephrectomy: Practice patterns in Canada
}

\author{
Thomas B. McGregor, MD'; Premal Patel, MD²; Gabriel Chan, MD; Alp Sener, MD
}

'Department of Urology, Queen's University, Kingston, ON; ${ }^{2}$ Section of Urology, University of Manitoba, Winnipeg, MB; ${ }^{3}$ Faculté de Médicine - Chirurgie, Université de Montréal, Montreal, QC; ${ }^{4}$ Division of Urology, Western University, London, ON; Canada

Cite as: Can Urol Assoc J 2017;11(10):321-4. http://dx.doi.org/10.5489/cuaj.4490

See related commentary on page 325

\section{Abstract}

Introduction: In recent years, the method of vascular control during laparoscopic donor nephrectomy (LDN) has come under scrutiny due to catastrophic consequences of a device failure. This study sought to examine the surgical preferences of Canadian donor surgeons with regards to vascular control and their perception on the safety of these modalities. We also surveyed the experience with device malfunction and their subsequent management during LDN. Methods: An online survey was sent out to donor surgeons registered with the Canadian Society of Transplantation. Surveys were anonymous and voluntary. Descriptive statistics were used to analyze the collected responses. Recollection of the sequelae and outcomes from device malfunction were also queried.

Results: Twenty-eight of 37 surgeons (76\% response rate) responded to the survey. At least one surgeon from every institution in Canada performing LDN responded to the survey. Laparoscopic stapler is the most commonly used device for securing the renal artery $(61 \%)$ and renal vein (67\%). Overall, surgeons felt the stapler was the safest method of securing the renal artery. Stapler misfire and clip slippage were reported by eight (28.5\%) and 12 (43\%) surgeons, respectively. Most cases were salvageable: laparoscopically $(30 \%)$, open conversion $(30 \%)$, and by hand port (5\%). Slippage of a plastic locking clip resulted in one emergent laparotomy on POD\#1 and one stapler misfire was converted to open resulting in donor death.

Conclusions: Although rare, hemorrhagic complications can occur from device malfunction resulting in poor outcomes for healthy volunteers undergoing LDN. Surgeons need to remain vigilant when selecting the appropriate modality for vascular control.

\section{Introduction}

Since the initial publication by Ratner in 1995, laparoscopic donor nephrectomy (LDN) has become the standard for living kidney donation. ${ }^{1}$ The minimally invasive technique is associated with improved cosmetics, decreased morbidity, a shorter length of stay, and a quicker return to work, all of which have led to increased living donation rates across the globe. ${ }^{2}$ The actual operation has evolved, with notable improvements in optics, surgical instrumentation, and energy sources. ${ }^{3}$

Several variations exist in terms of the incisions, the use of hand ports, the application of robotic assistance, and the extraction method for the graft; however, in recent years, the method of vascular control of the renal vessels has come under the most scrutiny due to catastrophic consequences of a device failure. ${ }^{3,4}$ The balance between safety and ensuring a sufficient donor vessel length for the transplantation anastomoses can be a fine line. The two most common modalities used to ligate and divide the artery and vein laparoscopically are surgical clips (non-transfixating) and staplers (transfixating). Each technique comes with a risk of malfunction: clip-slippage and stapler misfire, respectively. ${ }^{5}$

Surgical principles would imply that stapling is the safer of these two techniques, given that the staples actually transfix the vessel wall, as opposed to clips or ties that do not. There also exists suspicion that the incidence of stapler misfires and clip dislodgement during LDN are both under-reported in the literature. ${ }^{5}$ Furthermore, due to several reports of donor deaths related to locking clip slippage, the FDA has placed a warning that plastic locking clips (Weck ${ }^{\circledR}$ Hem-o-lok $^{\circledR}$ clips) are contraindicated for use on the donor artery during nephrectomy. ${ }^{6}$

The goal of this study is to survey the practice patterns of Canadian living kidney donor surgeons in regards to hilar control and poll their opinions as to the safety of each approach. Furthermore, this study aimed to better define the perceived incidence of device malfunction during LDN.

\section{Methods}

Following ethics approval by the University of Manitoba, surveys were sent by email to 37 kidney donor surgeons registered with the Canadian Society of Transplantation. All 
surveys were voluntary and the results were kept anonymous. The survey was distributed through an online survey platform (SurveyMonkey ${ }^{\circledR}$ ). The questions were grouped into several categories: technique of vascular control, perception of the safety of each method, and the incidence and consequences of device malfunction. Descriptive statistics were used to analyze the collected responses.

\section{Results}

The survey was conducted between January 2016 and October 2016. Twenty-eight of 37 identified kidney donor surgeons ( $76 \%$ response rate) from seven provinces across Canada responded to the anonymous survey and a response was received by at least one surgeon from every Canadian institution involved in performing renal transplant surgery. Of the 28 respondents, 11 were general surgeons, 16 were urologists, and one was a vascular surgeon. Responses with regards to institutional practice patterns are shown in Table 1.

The survey found that the majority (89\%) of respondents reported that their institution had between 1-3 donor surgeons, with all programs offering LDN. Case volume varied substantially, with $7 \%$ of surgeons performing more than 60 cases annually and $25 \%$ less than 20 donor nephrectomies annually. Of the 28 respondents, 15 (54\%) surgeons still offer open donor nephrectomy, with the majority of surgeons $(n=19)$ extracting the kidney through a Pfannenstiel incision. Cold storage was found to be the most common method for renal preservation $(93 \%)$.

Surgeon preference for the technique of hilar control also varied (Fig. 1). Eighteen surgeons secure the renal vein using a stapler, while nine reported the use of plastic locking $\left(\right.$ Weck $^{\circledR}$ Hem-o-lok ${ }^{\circledR}$ ) clips. As for the renal artery, 17 (61\%) surgeons secure the renal artery with a stapler, nine (32\%) use titanium clips, and the remaining two surgeons use either a Weck ${ }^{\circledR}$ Hem-o-lok ${ }^{\circledR}$ clip or a combination of titanium and Weck ${ }^{\circledR}$ Hem-o-lok ${ }^{\circledR}$ clips.

Fig. 2 illustrates each surgeon's opinion regarding the safety of various techniques for renal hilar control. Overall, the laparoscopic stapler was felt to be the safest method (62\%). Surgical opinion regarding the safety of nontransfixing techniques to control the renal vessels varied greatly.

Table 2 details surgical experience with regards to laparoscopic device malfunction. Nine surgeons $(27 \%)$ responded that their institution has had a stapler misfire during a LDN, with 11 (39\%) surgeons reporting misfires during a laparoscopic radical nephrectomy. Twelve $(43 \%)$ surgeons responded their

\begin{tabular}{|c|c|c|}
\hline Question & & $\begin{array}{c}\text { Response } \\
\quad(n, \%)\end{array}$ \\
\hline $\begin{array}{l}\text { How many donor } \\
\text { surgeons do you have } \\
\text { at your institution? }\end{array}$ & $\begin{array}{l}1-3 \\
4-6\end{array}$ & $\begin{array}{c}25(89 \%) \\
3(11 \%)\end{array}$ \\
\hline $\begin{array}{l}\text { Does your centre } \\
\text { perform laparoscopic } \\
\text { donor nephrectomy? }\end{array}$ & $\begin{array}{c}\text { Yes } \\
\text { No } \\
\text { If yes, purely laparoscopic } \\
\text { If yes, hand-assisted } \\
\text { If yes, robotic } \\
\text { If yes, some lap and some } \\
\text { robotic }\end{array}$ & $\begin{array}{c}28(100 \%) \\
0 \\
19(68 \%) \\
6(21.5 \%) \\
1(3.5 \%) \\
2(7 \%)\end{array}$ \\
\hline $\begin{array}{l}\text { How many donor } \\
\text { nephrectomies does } \\
\text { your institution } \\
\text { perform each year? }\end{array}$ & $\begin{array}{c}1-20 \\
21-40 \\
41-60 \\
61-80 \\
81-100 \\
\end{array}$ & $\begin{array}{c}7(25 \%) \\
12(43 \%) \\
7(25 \%) \\
1(3.5 \%) \\
1(3.5 \%) \\
\end{array}$ \\
\hline $\begin{array}{l}\text { Do you still offer open } \\
\text { donor nephrectomy? }\end{array}$ & $\begin{array}{c}\text { Yes } \\
\text { No } \\
\text { Full-flank incision } \\
\text { Mini-flank incision }\end{array}$ & $\begin{array}{l}15 \\
13 \\
4 \\
7\end{array}$ \\
\hline $\begin{array}{l}\text { How do laparoscopic } \\
\text { donor surgeons at } \\
\text { your centre usually } \\
\text { extract the kidney? }\end{array}$ & $\begin{array}{c}\text { Pfannenstiel } \\
\text { Hand-port } \\
\text { Extension of a port-site } \\
\text { LESS/NOTES }\end{array}$ & $\begin{array}{l}19 \\
10 \\
3 \\
1\end{array}$ \\
\hline $\begin{array}{l}\text { How is the kidney } \\
\text { usually preserved } \\
\text { prior to living donor } \\
\text { transplantation? }\end{array}$ & $\begin{array}{c}\text { Perfusion pump } \\
\text { Cold storage } \\
\text { Immediate transfer to } \\
\text { adjacent operating room for } \\
\text { transplantation }\end{array}$ & $\begin{array}{c}2 \\
26 \\
2\end{array}$ \\
\hline
\end{tabular}

centre has had experiences with surgical clips falling off. A majority of surgeons $(>80 \%$ ) believe the incidences of stapler misfire and surgical clip malfunction are under-reported in the literature. Outcomes from the various device malfunctions are shown in Table 3.

\section{Discussion}

This study found that the control and division of the renal hilar vessels is most commonly performed with stapling

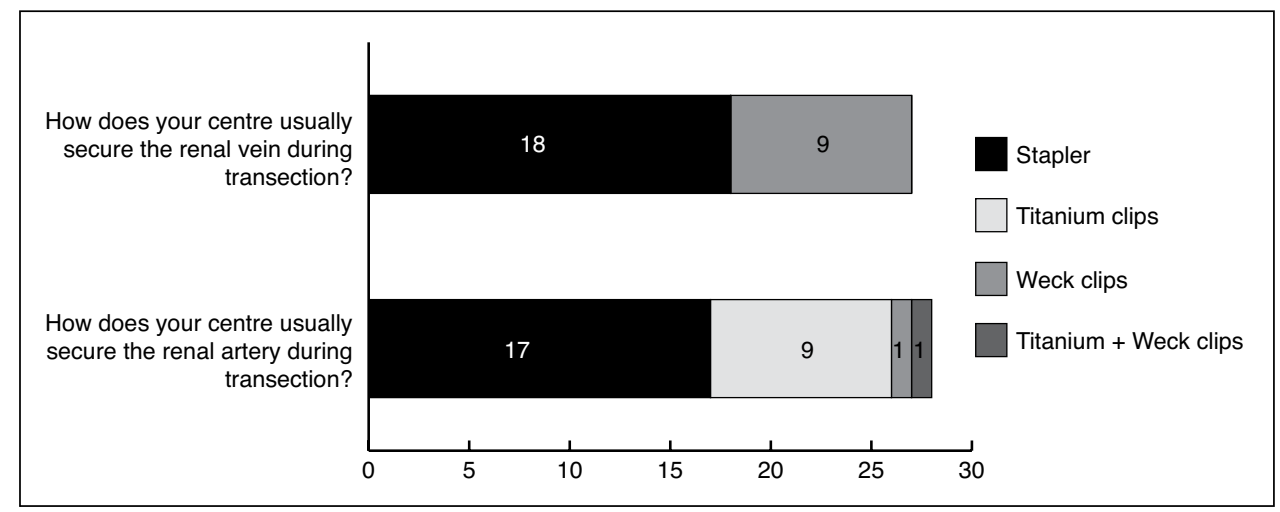

Fig. 1. Donor surgeon response with regards to their institutional practice patterns of controlling the hilar vessels. 


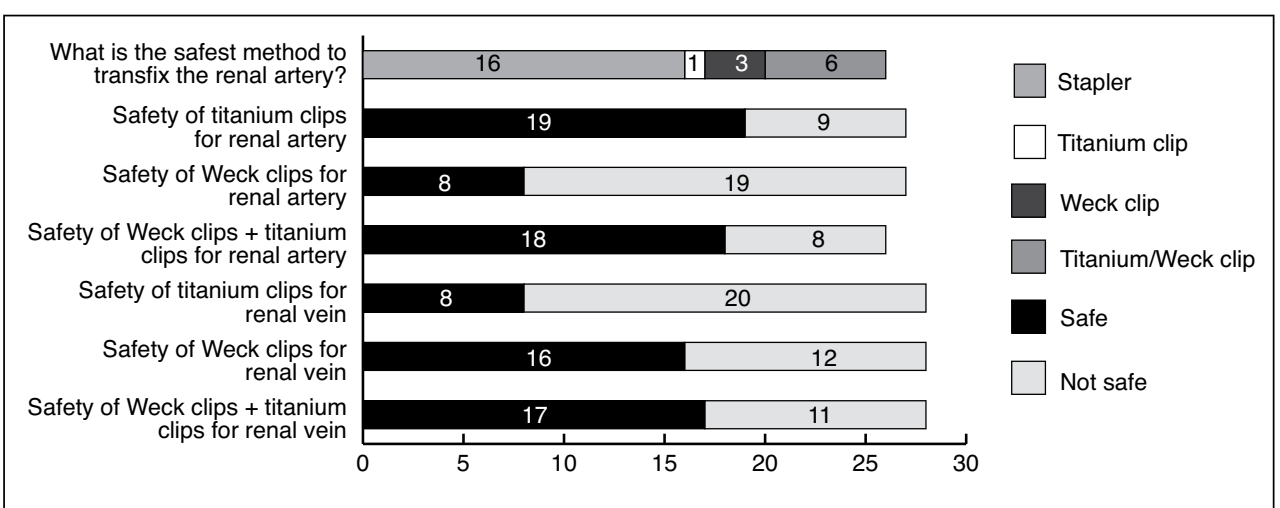

Fig. 2. Donor surgeon responses with regards to their opinion about the various modalities' ability to control the hilar vessels.

devices. These devices allow for the division and ligation of the artery or vein in one motion. The accepted sacrifice is the loss of a couple millimetres of length on the graft vessel. Although this study did not differentiate between different models or companies, the general assumption is that it is a device that staples and divides simultaneously. There is some suggestion in the literature that there is a trend towards the use of non-cutting staplers, as these eliminate two rows of staples, facilitating a longer vessel length, but would require an exchange of instruments to divide the vessel and a slightly longer warm ischemia time. However, when considering donor safety, the additional seconds of warm ischemic time is unlikely to be clinically significant.

It is worth noting that the reported vascular control technique differed between the artery and the vein. The stapler was the more frequently used to control the artery $(75 \%)$, whereas it was slightly less used (55\%) for renal venous control. Surprisingly, a minor percentage of transplant surgeons still continue to use locking polymer clips, either alone or in combination with titanium clips for either the artery or the vein despite the FDA statement highlighting their contraindication for use in securing the renal artery during LDN. ${ }^{6}$ This may potentially be related to practice patterns or surgeon

\begin{tabular}{llc}
\hline $\begin{array}{l}\text { Table 2. Donor surgeon responses with regards to } \\
\text { laparoscopic device malfunction }\end{array}$ & \\
\hline $\begin{array}{l}\text { Has your centre ever experienced a stapler } \\
\text { misfire during a laparoscopic donor } \\
\text { nephrectomy (that you of know of)? }\end{array}$ & Yes & $\begin{array}{c}8(28.5 \%) \\
20(71.5 \%)\end{array}$ \\
\hline $\begin{array}{l}\text { Has your centre ever experienced a stapler } \\
\text { misfire duration a laparoscopic radical }\end{array}$ & Yes & $11(39 \%)$ \\
nephrectomy (that you know of)? & No & $17(61 \%)$ \\
\hline $\begin{array}{l}\text { Has your centre ever had troubles/issues with } \\
\text { surgical clips (i.e., clips falling off)? }\end{array}$ & Yes & $12(43 \%)$ \\
\hline $\begin{array}{l}\text { Do you think the incidence of stapler misfire is } \\
\text { under-reported in the literature? }\end{array}$ & Yes & $23(57 \%)$ \\
\hline $\begin{array}{l}\text { Do you think the incidence of surgical } \\
\text { clip malfunction is under-reported in the }\end{array}$ & No & $5(18 \%)$ \\
literature? & No & $26(93 \%)$ \\
\hline
\end{tabular}

experience when performing radical nephrectomies, although this remains to be investigated. In the end, it is clear that more education regarding this warning is required to prevent further catastrophic vascular complications in living donors.

When asked specifically about the safety of each individual method for vascular control, the majority of surgeons $(57 \%)$ felt that the stapler was the safest means to secure the vessels; however, a surprising number of surgeons still feel that use of clips (non-transfixing techniques) are safe. Specifically, despite the contraindication for use in LDN, $24 \%$ of surgeons still feel the locking polymer clip to be safe, while $55 \%$ feel it is only safe when combined with a titanium clip. These results are concerning, especially with several reports of severe hemorrhagic complications in the literature related to clip slippage. In our study, $24 \%$ of surgeons reported occurrences with locking polymer clips falling off, one of which occurred on POD $\# 1$ resulting in an emergent laparotomy. Delayed slippage of clips is of the upmost concern because of the high risk of a fatal outcome., ${ }^{3,4}$

Despite the perceived superiority of the laparoscopic stapler, $27 \%$ of surgeons still reported experiencing a stapler misfire during LDN. This rate grew to $39 \%$ when asked about stapler misfire during other laparoscopic renal cases. The reported incidence of stapler misfire in this study was similar to that of clip slippage. Both stapler misfire and clip slippage lead to an array of outcomes, including emergent conversion to an open laparotomy. In most instances, device malfunction could be salvaged by various means, but one death was reported in this study following stapler misfire and conversion to open. The rates of stapler misfire and clip slippage have been reported to be as high as 3\% in

\begin{tabular}{ll}
\hline $\begin{array}{l}\text { Table 3. Morbidity and mortality of device malfunction } \\
\text { Device malfunction }\end{array}$ & \multicolumn{1}{c}{ Outcome } \\
\hline & $\begin{array}{l}\text { Salvaged with repeat stapler fire }(n=3) \\
\text { Salvaged with laparoscopic vascular clamp } \\
\text { and suture }(n=2)\end{array}$ \\
$\begin{array}{l}\text { Stapler misfire } \\
(n=9)\end{array}$ & $\begin{array}{l}\text { Salvaged with conversion to open }(n=1) \\
\text { Salvaged with hand-port }(n=1) \\
\text { Covert to open - death }(n=1)\end{array}$ \\
& Outcome not reported $(n=1)$ \\
\hline $\begin{array}{l}\text { Titanium clip } \\
\text { falling off }(n=4)\end{array}$ & $\begin{array}{l}\text { Salvaged with conversion to open }(n=3) \\
\text { Outcome not reported }(n=1)\end{array}$ \\
\hline & $\begin{array}{l}\text { Salvaged with conversion to open }(n=2) \\
\text { Weck }{ }^{\circledR} \text { Hem-o-lok }{ }^{\circledR}\end{array}$ \\
clip falling off (n=8) & $\begin{array}{l}\text { Vessel sheared, titanium clip reapplied }(n=1) \\
\text { Outcome not reported }(n=4)\end{array}$ \\
\hline
\end{tabular}


the literature, although the actual incidence is unknown. ${ }^{8}$ Most donor surgeons in this study suspect the incidence is under-reported. Further investigation into the causes of vascular stapler malfunction will be crucial to hopefully prevent future complications. The causes could include a technical error of including a titanium clip in the staple line, an error in mounting of the cartridge of staples, or a manufacturing error in the mechanism of the device. Since such device malfunctions are uncommon, a national or international prospective collaboration will be essential.

An important message that emerges from this high percentage of device failure, whether transfixing or not, is that all surgical devices are prone to malfunction and can lead to catastrophic complications. Resultant hemorrhage from a poorly secured renal artery can be brisk and difficult to control, even with immediate action and conversion to an open laparotomy. This highlights the inherent risk of performing major surgery on healthy volunteers for benefit of another patient. With the high stakes of LDN, the authors feel that potential, reasonable operative considerations could include: the mandatory attendance of two surgeons at all LDN cases (at minimum during the hilar dissection and transfixation and organ extraction), use of large bore intravenous catheters in all donors, arterial catheters for blood pressure monitoring, and the mandatory presence of cell savers in the operating room.

This study has several weaknesses inherent to its design. As is the case with all surveys, we are reliant on surgeon recollection and voluntary reporting of their preferences, opinions, and complications. A surgeon's choice of instrumentation to secure the renal vasculature may change from case to case dependent on anatomic variation, hospital equipment contracts, and previous experiences with complications. Also, several of the outcomes for device malfunction were not reported, leading to a potential underestimation of the morbidities and mortalities. Lastly, we were able to obtain a response rate of $76 \%$, which is reasonable and is a fairly wide national representation with at least one respondent from each transplant program.

\section{Conclusion}

Although rare, hemorrhagic complications can occur from device malfunction, resulting in poor outcomes for healthy volunteers undergoing LDN. With this in mind, surgeons need to remain vigilant when choosing their technique for vascular control. Although surgeon preference varies, the laparoscopic stapler is overwhelmingly the most used device and is perceived to be the safest means of securing the renal vessels. Despite this, device malfunction with major complications can occur with both stapling devices and surgical clips. Efforts to maintain donor safety are paramount to ensuring continued success of living kidney donor programs nationwide and emergency simulations should be performed routinely by the entire team of anesthesiologists, surgeons, and nurses so as to minimize morbidity and mortality associated with intraoperative complications during LDN.

Competing interests: Dr. Sener has received honoraria from Eli Lilly and CONMED; was the recipient of FirstKIND grants; and is co-founder of Clearwater Clinical Limited. The remaining authors report no competing personal or financial interests.

This paper has been peer-reviewed.

\section{References}

1. Ratner LE, Ciseck L, Moore RG, et al. Laparoscopic live donor nephrectomy. Transplantation 1995;60:1047-49

2. Rampersad C, Patel P, Koulack J, et al. Back-to-back comparison of mini-open vs. laparoscopic technique for living kidney donation. Can Urol Assoc J 2016;10:253-7. https://doi.org/10.5489/cuaj.3725

3. FriedmanAL, PetersTG, JonesKW, et al. Fatal and non-fatal hemorrhagic complications of living kidney donation. Ann Surg 2006;243:126-30. htrps://doi.org/10.1097/01.sla.0000193841.43474.ec

4. S. Janki S, Verver D, Klop KWJ, et al. Vascular management during live donor nephrectomy: An online survey among transplant surgeons. Am J Transplant 2015;15:1701-7. https://doi.org/10.1111/ait.13142

5. Kwazneski D, Six C, Stahlfeld K. The unacknowledged incidence of laparoscopic stapler malfunction. Surg Endosc 2013;27:86-9. https://doi.org/10.1007/s00464-012-2417-y

6. Auto Suture ENDO CLIP Disposable Clip Applier. Product Booklet, Copyright 1999, Norwalk, CT: United States Surgical Corporation.

7. Jellison FC, Shah SK, Mashni JW Jr, et al. Vessel length following laparoscopic donor nephrectomy: Impact of vascular ligation technique on allograft vessel length. J Endourol 2008;22:973-7. https://doi.org/10.1089/end.2007.0239

8. Cabello R, García JV, Quicios $C$, et al. Is there a new alternative for a safer kidney artery ligation in laparoscopic donor nephrectomy? J Laparoendosc Adv Surg Tech A 2017;27:715-6. https://doi.org/10.1089/lap.2016.0271

Correspondence: Dr. Thomas B. McGregor, Department of Urology, Queen's University, Kingston, ON, Canada; mcgregot@kgh.kari.net 